\title{
A FORMAÇÃO SUPERIOR PARA O SECRETARIADO NA PERSPECTIVA LUSO- BRASILEIRA
}

\section{THE HIGHER EDUCATION TO THE SECRETARIES IN LUSO-BRAZILIAN PERSPECTIVE}

\section{Rosimeri Ferraz Sabino}

Doutoranda em Educação pela Universidade Federal de Sergipe - UFS.

Professora Assistente do Departamento de Secretariado Executivo da Universidade Federal de Sergipe - UFS.

E-mail: rf.sabino@gmail.com (Brasil)

\section{Vitor Manuel Barrigão Gonçalves}

Doutorado em Engenharia Electrotécnica e de Computadores pela Universidade do Porto - U.PORTO.

Professor Adjunto do Instituto Politécnico de Bragança - Portugal.

E-mail: vg@ipb.pt (Portugal) 


\title{
A FORMAÇÃO SUPERIOR PARA O SECRETARIADO NA PERSPECTIVA LUSO- BRASILEIRA
}

\section{RESUMO}

O objetivo deste estudo foi verificar como se constitui a formação tecnológica para o Secretariado no Brasil e em Portugal, identificando as características da educação formal e a oferta de cursos superiores para esse público, compondo uma análise comparativa do panorama dessa formação nos dois países. Com o embasamento em legislações educacionais e para o trabalho e, ainda, em referenciais sobre o ensino superior no âmbito brasileiro e internacional, a pesquisa se constitui como um estudo de caso, associado ao método comparativo. Os resultados apontam para a tendência da formação tecnológica para os secretários, em detrimento aos de longa duração, trazendo como desafios a ambos os países o acompanhamento dos debates e tendências para o ensino superior, a observação e articulação das demandas à preparação de novos profissionais e a identificação das influências nas expectativas e escolhas de carreira da população jovem.

Palavras-Chave: educação superior; ensino tecnológico; secretariado; sistema educacional brasileiro; sistema educacional português.

\section{THE HIGHER EDUCATION TO THE SECRETARIES IN LUSO-BRAZILIAN PERSPECTIVE}

\begin{abstract}
The aim of this study is to verify the process of technological graduation for secretariat students in Brazil and Portugal, identifying the characteristics of formal education and the provision of higher education for this public, making a comparative analysis of the scenario of this graduation in both countries. Based on educational and work legislation, and also in reference to higher education in Brazil and other countries, the research is a case study, associated to the comparative method. The results indicate a growth in the trend of technological graduation for secretaries, bringing challenges to both countries in order to monitor the debates and trends in higher education, and also to observe and articulate demands to prepare new professionals and to identify the influences on young people's expectations and career choices.
\end{abstract}

Keywords: brazilian educational system; higher education; portuguese educational system; secretariat; technological education. 


\section{Introduçãa}

A expansão do ensino superior em nível mundial, intensificada a partir de 1960, não apenas elevou o número de estudantes como, também, promoveu mudanças nos sistemas de ensino para o terceiro grau. Em decorrência da ampla gama de ocupações diferenciadas trazidas pela sociedade pós-industrial, o sistema clássico e as formações técnicas-profissionais enfrentaram um processo de diversificação institucional que elevou a educação vocacional para o nível terciário (Porto \& Régnier, 2003; Schwartzman, 2005). Isso ocorreu por meio da inclusão de programas vocacionais no circuito universitário com: a transformação de programas ou instituições secundárias para um nível terciário profissional; a introdução de cursos universitários de curta duração; o desenvolvimento de cursos para atendimento a setores privados; a inclusão de experiências de trabalho ou estudos aplicados nos programas convencionais; a participação em estudos de nível terciário em outras instituições, e promoção de cooperação entre segmentos e fronteiras (Wagner, 1998).

Nesse contexto, entre as políticas para a articulação do ensino superior à qualificação para o trabalho surgiram os cursos de curta duração, desenvolvidos pelos community colleges ou institutos politécnicos. Não obstante às peculiaridades dos sistemas de ensino dos diferentes países, implicando distintas nomenclaturas e hierarquia na escala de continuidade, esses cursos visam ampliar o percentual de pessoas com qualificação superior, respondendo mais rapidamente às demandas do mercado. Embora suscetível às críticas sobre uma educação caracterizada como economicista (Amaral \& Teixeira, 2000; Curaj, Schott, Vlasceanu \& Wilson, 2012), há a consideração de que esse formato constitui um canal para o maior acesso ao ensino superior por camadas menos favorecidas (Castro \& Levy, 2000).

Com o interesse de se investigar o cenário que emerge dessa expansão do ensino superior, pela via dos cursos de curta duração para a formação de secretários, optou-se pela análise das realidades brasileira e portuguesa. A escolha pautou-se pelas peculiaridades do Secretariado evidenciadas nos dois países: o Brasil é o único país em que o Secretariado recebe o credenciamento de profissão regulamentada, pelas Leis 6.556 (1978), 7.377 (1985) e 9.261 (1996), e Portugal apresentou o significativo "crescimento de 60\% dos processos de recrutamento em 2015" para os postos de secretários (Michael Page, 2016), sendo apontado para esse resultado a valorização da formação superior vocacionada para a ocupação. 
Assim, buscou-se verificar como se constitui a formação tecnológica para o Secretariado no Brasil e em Portugal, identificando as características da educação formal, diante de cada sistema de ensino, e a oferta de cursos superiores para esse público, compondo uma análise comparativa do panorama da formação superior tecnológica para os secretários desses países. Com o embasamento em legislações educacionais e para o trabalho e, ainda, em referenciais sobre o ensino superior no âmbito brasileiro e internacional, a pesquisa se constitui como um estudo de caso (Yin, 2015; Woodside, 2010), associado ao método comparativo, com vistas à identificação de similaridades ou variações entre as realidades pesquisadas. As análises foram desenvolvidas sob abordagem qualiquanti (Teddlie \& Tashakkori, 2003), possibilitando interpretações sobre o contexto e resultados estatísticos encontrados.

A organização do estudo apresenta, a partir desta introdução, o referencial teórico, a metodologia utilizada, a análise dos resultados e, por fim, as considerações sobre a investigação, as quais apontam para a tendência na oferta da formação tecnológica, em detrimento aos cursos de longa duração, com maior ênfase desse cenário no Brasil.

\section{Referencial Teórico}

Entre os debates promovidos na Conferêncial Mundial sobre Educação Superior, ocorrida em Paris, em 1998, constou o desafio da conexão entre esse nível de ensino e o mercado de trabalho. O evento que contou com 4.000 participantes e culminou nos documentos "Declaração Mundial sobre a Educação Superior no Século XXI: visão e ação" e "Marco de ação prioritária para a mudança e o desenvolvimento da educação superior", colocou as formações superiores e o emprego no centro das discussões, mencionando que "No futuro, pressupõe-se que o ensino superior: [...] Diversifique mais suas estruturas e, portanto, as condições dos estudos e dos ensinamentos oferecidos; [...] Implemente formas de comunicação regulares entre o ensino superior e o mundo do trabalho" (Teichler, 1999, p. 325)

A preocupação com a aproximação das formações superiores às necessidades das forças produtivas já se evidenciava no Brasil no início da década de 1960, com a criação dos cursos superiores tecnológicos. Por meio do Parecer $n^{\circ} 60$ do Conselho Federal de Educação, aprovado em fevereiro de 1963, surgiu a proposta de uma nova modalidade para a formação na área da Engenharia. O Parecer $n^{0} 25$ do Conselho Federal de Educação, aprovado em 4 de fevereiro de 1965, conceituou essa formação como “elemento de formação tecnológica, de nível superior, com 
formação e treinamento em cursos de duração de três anos, para habilitação a supervisão de setores especializados da indústria e encargos normais da produção industrial” (Nascimento, 2007, p. 284). Na evolução dessa modalidade no Brasil, em 2002, o Ministério da Educação estabeleceu as diretrizes para a organização e o funcionamento dos cursos superiores de tecnologia, caracterizando essa formação como "integrada às diferentes formas de educação, ao trabalho, à ciência e à tecnologia, [objetivando] garantir aos cidadãos o direito à aquisição de competências profissionais que os tornem aptos para a inserção em setores profissionais nos quais haja utilização de tecnologias" (Brasil, 2002, p. 162). Conforme aquele órgão regulador, os cursos devem:

I - incentivar o desenvolvimento da capacidade empreendedora e da compreensão do processo tecnológico, em suas causas e efeitos; II - incentivar a produção e a inovação científico-tecnológica, e suas respectivas aplicações no mundo do trabalho; III desenvolver competências profissionais tecnológicas, gerais e específicas, para a gestão de processos e a produção de bens e serviços; IV - propiciar a compreensão e a avaliação dos impactos sociais, econômicos e ambientais resultantes da produção, gestão e incorporação de novas tecnologias; $\mathrm{V}$ - promover a capacidade de continuar aprendendo e de acompanhar as mudanças nas condições de trabalho, bem como propiciar o prosseguimento de estudos em cursos de pós-graduação; VI - adotar a flexibilidade, a interdisciplinaridade, a contextualização e a atualização permanente dos cursos e seus currículos; VII - garantir a identidade do perfil profissional de conclusão de curso e da respectiva organização curricular. (Brasil, 2002, p. 162).

O avanço, em nível mundial, da inclusão da formação tecnológica na educação superior (Schwartzman, 2005), é constatado também em Portugal, onde o Ministério da Educação e Ciência (MEC), por meio do Decreto-lei n. ${ }^{\circ} 43$, de 2014, criou “[...] um novo tipo de formação superior curta não conferente de grau, os cursos técnicos superiores profissionais" (Portugal, 2014, p. 2074). Esses cursos devem, de acordo com a mencionada legislação, ser ministrados em instituições de ensino politécnico, servindo como "oferta educativa de natureza profissional situada no nível 5 do Quadro Europeu de Qualificações para a Aprendizagem ao Longo da Vida” (Portugal, 2014, p. 2074), o qual articulado aos descritores do Quadro Nacional de Qualificações português estabelece como resultado de aprendizagem:

Conhecimento: Conhecimentos abrangentes, especializados, factuais e teóricos numa determinada área de estudo ou de trabalho e consciência dos limites desses conhecimentos; Aptidões: Uma gama abrangente de aptidões cognitivas e práticas necessárias para conceber soluções criativas para problemas abstratos; Atitudes; Gerir e supervisionar em contextos de estudo ou de trabalho sujeitos a alterações imprevisíveis. Rever e desenvolver o seu desempenho e o de terceiros. (ANQEP, 2015).

Em ambos os países resta clara a intenção da formação tecnológica como via de qualificação de pessoal diante das demandas socioeconômicas. A distinção no cenário luso-brasileiro dá-se pelo espaço dessa formação no âmbito do ensino superior. Enquanto o Brasil define os cursos tecnológicos como superiores, colocando-os no mesmo patamar dos bacharelados no tocante à 
continuidade acadêmica, o sistema de ensino português mantém esses cursos sob um princípio de terminalidade. O prosseguimento dos estudos acadêmicos lusitanos está, assim, dependente de um curso que atribua um grau acadêmico, que seria o de licenciatura. Para melhor compreensão, expõem-se nas Figuras 1 e 2, a seguir, os sistemas de cada país a partir do nível secundário:

Figura 1 - Sistema de ensino português.

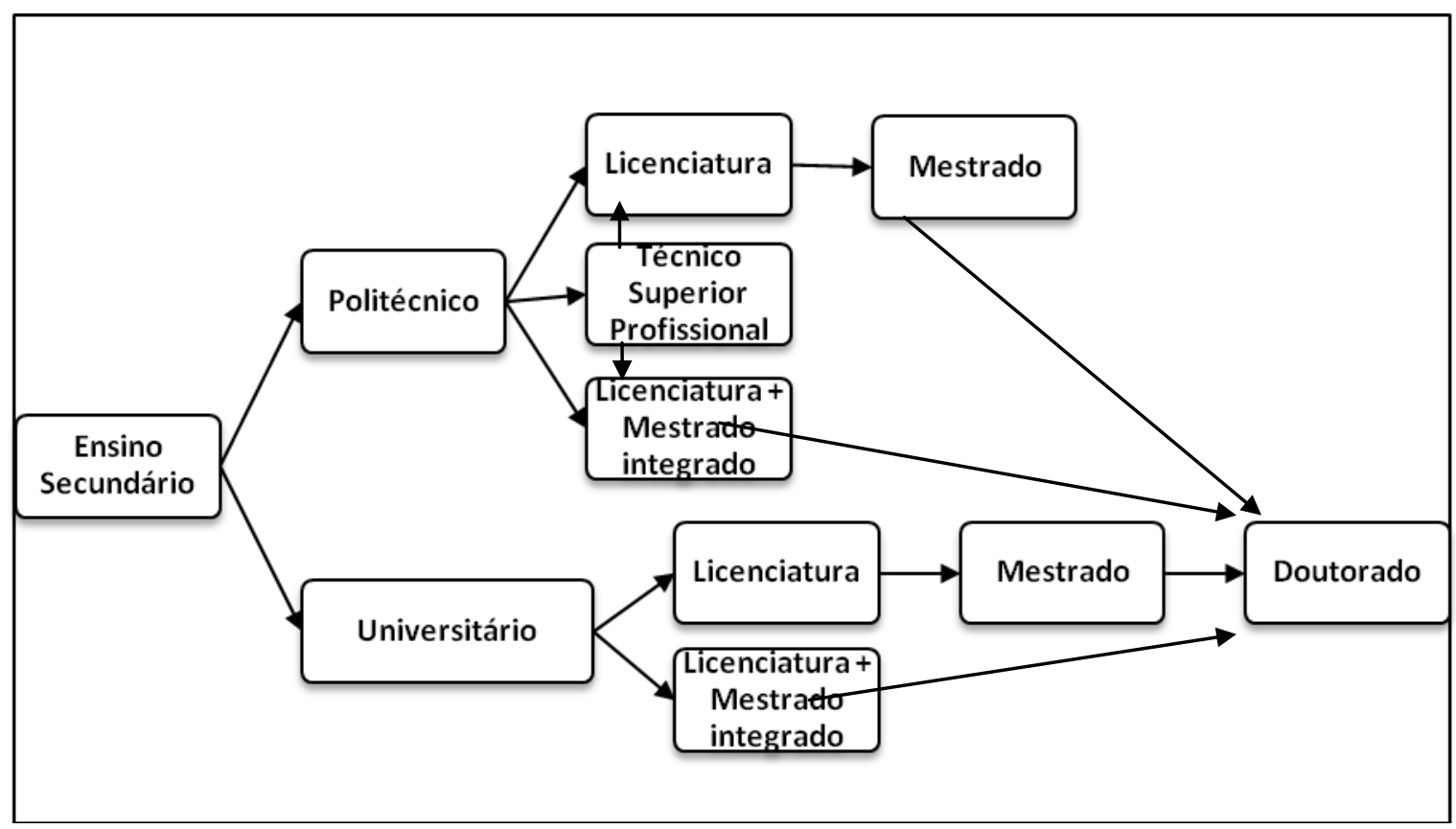

Fonte: Elaborado pelos autores, com base em DGES (2015).

Figura 2 - Sistema de ensino brasileiro.

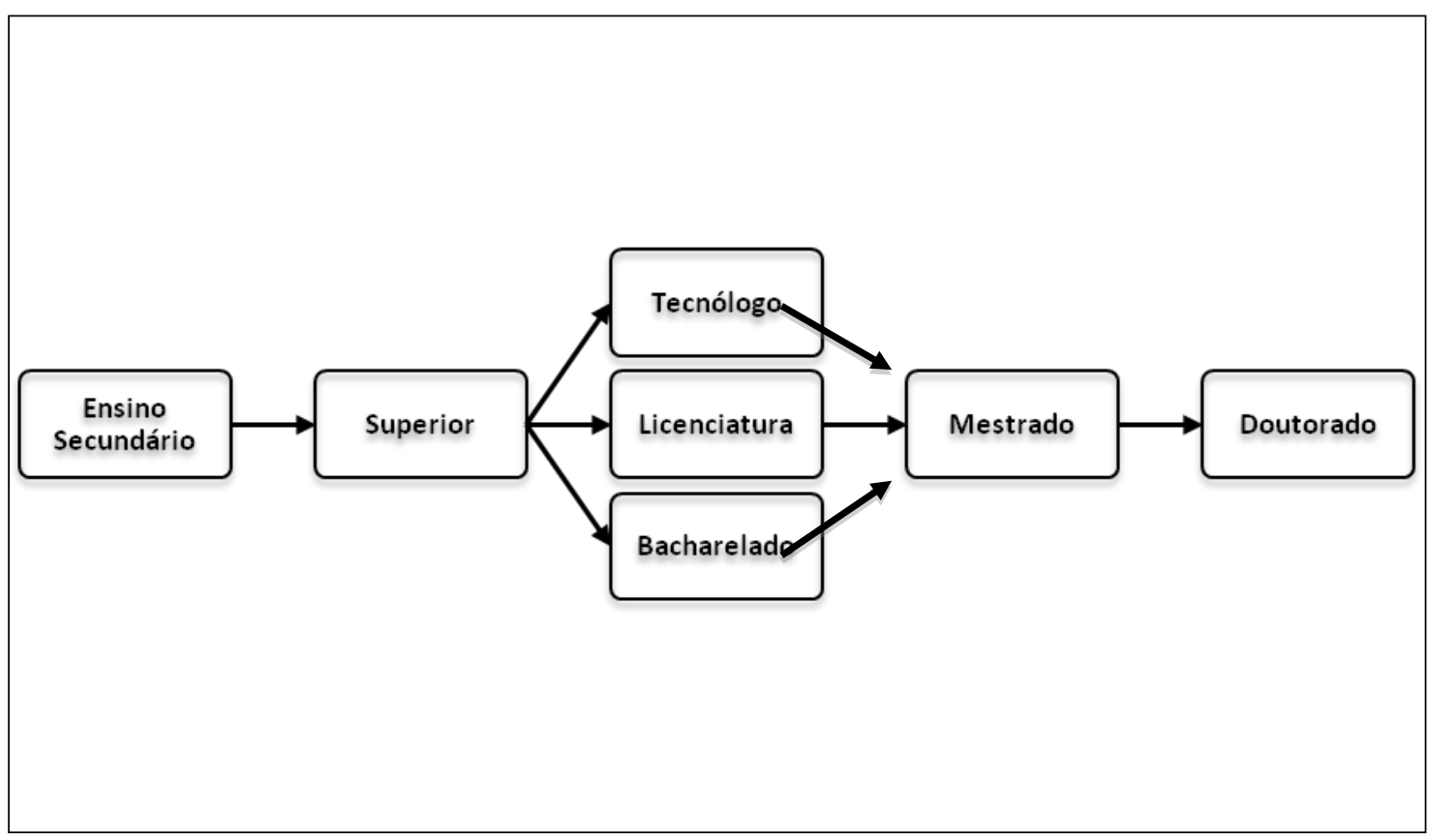

Fonte: Elaborado pelos autores, com base em Portal Brasil (2015).

Revista de Gestão e Secretariado - GeSec, São Paulo, v. 7, n. 1, p. 150-171,jan./abr. 2016. 
A resposta sobre a procura dos cursos tecnológicos é observada no índice de crescimento em torno de $680 \%$ das matrículas em Portugal, em relação ao primeiro ano de funcionamento dessa formação (Silva, 2015), e da média anual de 24,1\% no crescimento de matrículas no período entre 2003 a 2013, no Brasil, correspondendo a 13,6\% de matrículas no ensino superior, no ano seguinte (Portal Brasil, 2016). Esse quadro aponta para a procura pelos estudantes de uma formação em menor tempo, possibilitando um ingresso mais rápido no mercado de trabalho.

Em relação à formação de secretários, a preferência pelos cursos de Tecnólogo em Secretariado no Brasil é identificada na ampliação dessa oferta nos últimos anos, enquanto ocorre uma redução dos cursos de Bacharel em Secretariado Executivo (Cielo, Schmidt \& Wenningkamp, 2014). Já em Portugal, o baixo índice de crescimento dos cursos de Licenciatura em Secretariado suscita que essa formação "[...] não tem o impacto desejado no mercado de trabalho ou perde espaço para outras estruturas de formação na área" (Vieira \& Sousa, 2015, p. 19) . Cabe ressaltar que os cenários legais para o Secretariado nos dois países são distintos: apenas no Brasil a profissão é regulamentada. Disso decorre a formação condicional para a atuação no mercado de trabalho.

As legislações brasileiras para o exercício da profissão de secretário em nível executivo mencionam a exigência de "curso superior", abarcando, portanto, os cursos de bacharelado e os superiores de tecnologia. Uma vez que o credenciamento da profissão não especifica a modalidade do nível superior, os cursos tecnológicos proporcionam aos egressos o mesmo status formativo que os cursos bacharelados, com o benefício de uma menor duração e possibilidade de colocação mais rápida no mercado de trabalho. $\mathrm{O}$ entendimento sobre a equivalência na empregabilidade dos dois títulos se comprova na descrição da ocupação de secretário executivo na Classificação Brasileira de Ocupações (2012), que a identifica, sob o código 2523-05, como: “Assessor de diretoria, Assessor de presidência, Assistente de diretoria, Assistente de presidência, Auxiliar administrativo de diretoria, Auxiliar administrativo de presidência, Secretário de diretoria, Secretário de gabinete, Secretário de presidência, Secretário pleno, Secretário sênior, Tecnólogo em secretariado" (CBO, 2012) (grifo nosso).

A contribuição da formação tecnológica para o ingresso dos secretários brasileiros no mercado de trabalho é constatada em pesquisas realizadas pelo Núcleo Brasileiro de Estágios (Nube) sobre a média da bolsa-auxílio para estagiários no período de 2011 a 2014. No ranking dos dez estágios melhores remunerados, o curso de Bacharel em Secretariado Executivo consta apenas no ano de 2011, sendo substituído nos últimos três anos do período pelo curso de Tecnólogo em Secretariado, conforme Quadro 1, a seguir: 
Quadro 1 - A formação superior em Secretariado no Brasil no ranking dos dez estágios com melhor remuneração, no período 2011-2014.

\begin{tabular}{|c|c|c|c|c|}
\hline Curso & 2014 & 2013 & 2012 & 2011 \\
\hline Bacharel em Secretariado Executivo & $\begin{array}{l}\text { Não } \\
\text { constou }\end{array}$ & $\begin{array}{l}\text { Não } \\
\text { constou }\end{array}$ & $\begin{array}{l}\text { Não } \\
\text { constou }\end{array}$ & $3^{\circ}$ lugar \\
\hline Tecnólogo em Secretariado & $8^{\circ}$ lugar & $2^{\circ}$ lugar & $1^{\circ}$ lugar & $\begin{array}{l}\text { Não } \\
\text { constou }\end{array}$ \\
\hline
\end{tabular}

Fonte: Elaborado pelos autores, com base em Núcleo Brasileiro de Estágios (Nube) (2015).

A observação sobre a inserção do estudante no mercado de trabalho ainda durante a sua formação, por via de estágios, torna-se relevante para a análise da própria oferta educativa. O potencial de um curso ser requisitado pelas organizações empregadoras oferece ao aluno uma perspectiva sobre a sua empregabilidade quando egresso, podendo se tornar um aspecto de avaliação pelo estudante na escolha da formação. A atenção sobre o mercado para a sua futura profissão “[...] está presente nos jovens, não só durante os últimos anos do curso mas também no momento em que estes escolhem a instituição e o curso (Valle \& Rebelo, 2001 como citado em Ribeiro, 2008, p. 72). Constata-se, então, que as oportunidades que uma carreira possa oferecer exercem forte influência na escolha de uma formação, implicando planejamento das ofertas pelas instituições de ensino (Maringe, 2006).

\section{Metodologia}

A pesquisa, de natureza exploratória e descritiva (Majumdar, 2005; Gray, 2014), se consolida em um estudo de caso na medida em que buscou conhecer a realidade de uma formação superior específica na delimitação de dois países (Yin, 2015; Woodside, 2010). Para a verificação dos sistemas de ensino e das condições da oferta educacional em nível superior para secretários no Brasil e Portugal adotaram-se referências variadas, como estudos teóricos, legislações e dados estatísticos. Com o levantamento sobre os cenários investigados, passou-se à análise comparativa, sob abordagem quali-quanti (Teddlie \& Tashakkori, 2003).

Inicialmente, verificou-se como se constitui o sistema educacional de cada país, a partir do ensino secundário, com buscas nos sites e em legislações de diretrizes educacionais dos governos brasileiro e português. Essa etapa foi fundamental para a compreensão não só do lugar ocupado pela formação superior em Secretariado nos respectivos sistemas como, também, para a identificação 
dos caminhos possíveis para a evolução acadêmica dos egressos. Incluiu-se nas buscas a identificação de eventuais diretrizes voltadas para a formação superior de secretários em cada país.

A partir disso, verificou-se a oferta de cursos superiores de Secretariado, tendo como fonte os sites do Ministério da Educação brasileiro e da Direcção Geral do Ensino Superior do Ministério a Educação e Ciência de Portugal. Embora com especial interesse nos cursos de curta duração, chamados tecnológicos no Brasil e superior profissional em Portugal, entendeu-se necessário como subsídio às análises o levantamento dos cursos de todas as modalidades, desde que inseridos no âmbito da educação superior.

Os dados sobre a realidade brasileira revelaram um universo de cursos de substancial extensão (tecnológicos e de bacharelado), não se adequando a uma exposição nominal das instituições neste trabalho. Isso implicou a decisão por tratar as informações sobre as instituições de ensino brasileiras apenas estatisticamente. Já sobre a realidade portuguesa, foram identificadas nominalmente as instituições de ensino com a oferta da formação. Diante dos títulos encontrados em cada país, os cursos foram caracterizados em relação à composição em carga horária mínima, modalidade e âmbito de administração (público ou privado).

Tais procedimentos visaram compor um quadro de cada país para, em análise, se identificar eventuais semelhanças ou distinções entre as realidades investigadas. No entanto, durante as etapas iniciais contatou-se a necessidade de se observar, também, o comportamento da profissão nos respectivos mercados, uma vez que foram encontradas evidências de baixo crescimento ou de declínio na oferta de cursos superiores para secretários nos dois países. Considerou-se para isso a estreita ligação entre a escolha de uma formação e as possibilidades de empregabilidade, identificada nos referenciais da pesquisa.

Dessa forma, os procedimentos metodológicos viabilizaram atender os objetivos propostos para a pesquisa, permitindo uma análise comparativa sobre o panorama da formação tecnológica para os secretários no cenário luso-brasileiro. Embora com foco nos cursos de curta duração, o estudo abarcou outras modalidades do ensino superior para os secretários, conforme o respectivo sistema educacional dos países, com a finalidade de avaliar a evolução da formação tecnológica para o Secretariado. 


\section{Análise e Discussão dos Resultados (3)}

O sistema de ensino superior de Portugal atende à Declaração de Bolonha, de 19 de junho de 1999, que visou construir "[...] um espaço europeu de ensino superior globalmente harmonizado" (DGES, 2016). Nesse sistema, é utilizado o European Credit Transfer Systems (ECTS), “[...] criado pela Comissão das Comunidades Europeias, com o objectivo de gerar procedimentos comuns que garantissem o reconhecimento da equivalência académica dos estudos efectuados noutros países". Cada ECTS equivale entre 25 a 30 horas. Os graus acadêmicos consistem em licenciaturas, com duração de três anos ou 180 ECTS; mestrados, com duração entre 18 a 24 meses ou 90 a 120 créditos; e doutorados com duração entre três a quatro anos ou entre 180 a 240 ECTS. Há, ainda, os cursos de mestrados integrados, associando licenciatura e mestrado em um período entre cinco e seis anos ou entre 300 a 360 ECTS. A oferta desses cursos é normatizada pelo Decreto $\mathrm{n}^{\mathrm{0}} 74$, de 2006, que em seu artigo $4^{\text {o }}$ dispõe: “[...] 1- No ensino politécnico, são conferidos os graus académicos de licenciado e de mestre; 2- No ensino universitário, são conferidos os graus académicos de licenciado, mestre e doutor".

Em 2014, o Decreto-Lei n. ${ }^{\circ} 43$ criou, no âmbito dos Institutos Politécnicos portugueses, os Cursos Técnicos Superiores Profissionais (CTSP), com duração de dois anos ou 120 ECTS. Embora conste na estrutura do ensino superior, essa formação não recebe grau acadêmico e, conforme o mencionado decreto, vieram substituir

[...] progressivamente os cursos de especialização tecnológica, beneficiando da capacidade de formação existente nas instituições que ministram ensino superior politécnico ao nível da licenciatura e do mestrado. A oferta dos cursos de especialização tecnológica, que têm a natureza de cursos pós-secundários não superiores, manter-se-á no âmbito das instituições de ensino e de formação profissional não superiores, respondendo a necessidades do mercado de trabalho distintas daquelas a que se visa prover através dos cursos técnicos superiores profissionais. (Portugal, 2014).

O prosseguimento dos estudos a partir dos CTSPs só é possível por meio dos cursos de licenciaturas, os quais permitem o acesso aos cursos de mestrado. A formação superior para os secretários portugueses ocorre em Cursos Técnicos Superiores Profissionais e Licenciaturas, o que resulta aos interessados na continuidade acadêmica na necessidade de cursar uma licenciatura. A principal oferta dos cursos CTSPs e licenciaturas alocados na área 346- Secretariado e trabalho administrativo, conforme a Classificação Nacional de Áreas de Educação e Formação (CNAEF) é exposto no Quadro 2, a seguir: 
Quadro 2 - Oferta de cursos de Secretariado em Portugal.

\begin{tabular}{|c|c|c|c|}
\hline NÍVEL & CURSO & INSTITUIÇÃO & $\hat{\mathbf{A M B I T O}}$ \\
\hline \multirow[t]{5}{*}{$\begin{array}{l}\text { Técnico Superior } \\
\text { Profissional } \\
\text { (CTSP) }\end{array}$} & $\begin{array}{l}\text { Gestão clínica e } \\
\text { administrativa }\end{array}$ & $\begin{array}{l}\text { Instituto Politécnico da Guarda - Escola } \\
\text { Superior de Tecnologia e Gestão e } \\
\text { Escola Superior de Saúde da Guarda }\end{array}$ & Público \\
\hline & $\begin{array}{c}\text { Práticas Administrativas } \\
\text { e Comunicação } \\
\text { Empresarial }\end{array}$ & $\begin{array}{l}\text { Instituto Politécnico de Leiria - Escola } \\
\text { Superior de Educação e Ciências Sociais }\end{array}$ & Público \\
\hline & $\begin{array}{l}\text { Secretariado de } \\
\text { Administração }\end{array}$ & $\begin{array}{l}\text { Instituto Politécnico de Portalegre - } \\
\text { Escola Superior de Tecnologia e Gestão }\end{array}$ & Público \\
\hline & Secretariado e Línguas & $\begin{array}{l}\text { Instituto Politécnico de Bragança - } \\
\text { Escola Superior de Educação e Escola } \\
\text { Superior de Tecnologia e Gestão de } \\
\text { Bragança }\end{array}$ & Público \\
\hline & Secretariado Executivo & $\begin{array}{l}\text { Universidade do Algarve - Escola } \\
\text { Superior de Gestão, Hotelaria e Turismo }\end{array}$ & Público \\
\hline \multirow[t]{9}{*}{ Licenciatura } & $\begin{array}{l}\text { Assessoria de } \\
\text { administração }\end{array}$ & $\begin{array}{l}\text { Universidade do Algarve - Escola } \\
\text { Superior de Gestão, Hotelaria e Turismo }\end{array}$ & Público \\
\hline & Assessoria e Tradução & $\begin{array}{l}\text { Instituto Politécnico do Porto - Instituto } \\
\text { Superior de Contabilidade e } \\
\text { Administração do Porto }\end{array}$ & Público \\
\hline & Secretariado & $\begin{array}{l}\text { Instituto Politécnico de Castelo Branco - } \\
\text { Escola Superior de Educação de Castelo } \\
\text { Branco }\end{array}$ & Público \\
\hline & $\begin{array}{l}\text { Secretariado de } \\
\text { administração }\end{array}$ & $\begin{array}{l}\text { Instituto Politécnico de Viseu - Escola } \\
\text { Superior de Tecnologia e Gestão de } \\
\text { Lamego }\end{array}$ & Público \\
\hline & $\begin{array}{l}\text { Secretariado de direção e } \\
\text { administração }\end{array}$ & $\begin{array}{l}\text { Instituto Politécnico de Coimbra - } \\
\text { Instituto Superior de Contabilidade e } \\
\text { Administração de Coimbra }\end{array}$ & Público \\
\hline & $\begin{array}{l}\text { Secretariado e assessoria } \\
\text { de direção }\end{array}$ & $\begin{array}{l}\text { Instituto Politécnico da Guarda - Escola } \\
\text { Superior de Tecnologia e Gestão }\end{array}$ & Público \\
\hline & $\begin{array}{c}\text { Secretariado (Assessoria } \\
\text { de direção e } \\
\text { administração) }\end{array}$ & Instituto Superior de Novas Profissões & Privado \\
\hline & Secretariado clínico & $\begin{array}{l}\text { CESPU - Instituto Politécnico de Saúde } \\
\text { do Norte - Escola Superior de Saúde do } \\
\text { Vale do Ave }(*)\end{array}$ & Privado \\
\hline & $\begin{array}{c}\text { Secretariado e } \\
\text { comunicação empresarial }\end{array}$ & Universidade Européia $(* *)$ & Privado \\
\hline
\end{tabular}

\begin{tabular}{ccc} 
Mestrado & $\begin{array}{c}\text { Assessoria de } \\
\text { administração }\end{array}$ & $\begin{array}{c}\text { Instituto Politécnico do Porto - Instituto Público } \\
\text { Superior de Contabilidade e } \\
\text { Administração do Porto }\end{array}$ \\
\hline
\end{tabular}

Fonte: Elaborado pelos autores, com base em Direcção Geral do Ensino Superior/Portugal (2015).

(*): O curso não consta em funcionamento no site institucional.

(**) O curso consta como “descontinuado” nos registros da Direcção Geral do Ensino Superior/Portugal.

Observa-se que a formação para secretários portugueses tem maior oferta em nível de licenciatura, com sete instituições públicas e uma privada. Ressalta-se que dois cursos, sob administração privada, embora constem no registro da DGES, não foram confirmados em funcionamento nos sites das respectivas instituições. Isso levou a não considerá-los nas análises. Já

Revista de Gestão e Secretariado - GeSec, São Paulo, v. 7, n. 1, p. 150-171,jan./abr. 2016. 
os CTSPs contam com cinco ofertas, todos em instituições públicas. Esse cenário torna-se curioso quando analisado diante da história da formação para o Secretariado em Portugal. Ainda ao final da década de 1960 a formação em Secretariado ofertada, desde 1962, no antigo Instituto Superior de Línguas e Administração (ISLA), atual Universidade Europeia (Vieira \& Sousa, 2015) recebeu o reconhecimento de curso superior. Após cinco décadas, a formação parece mais promissora no âmbito do CTSPs, pois com recente regulamentação já contam com um contingente equivalente a $71 \%$ dos cursos de licenciaturas. Considerando que a evolução acadêmica no sistema português ocorre a partir dos cursos de licenciaturas, um eventual desequilíbrio entre as ofertas de CTSPs e licenciaturas poderá acarretar limitações na qualificação do universo de egressos em Secretariado.

A averiguação sobre a colocação dos egressos dos cursos CTSPs e licenciaturas para o Secretariado no mercado de trabalho é acompanhada pelo Ministério da Educação e Ciência (MEC) português. Embora não sendo identificados dados de todas as instituições ofertantes, os números encontrados acerca de quatro dessas instituições, todas do âmbito público, revelam um índice médio de desemprego de 6,15\% dos egressos. O maior índice é o de Licenciatura em Assessoria e Tradução do Instituto Superior de Contabilidade e Administração de Porto (Iscap), com 8\% de desemprego entre os egressos, e o menor, com 4,4\%, o de Licenciatura em Assessoria de Administração da Universidade do Algarve - Escola Superior de Gestão, Hotelaria e Turismo (MEC, 2016).

Os cursos CTSPs para o Secretariado português se caracterizam com um mínino de 3.240 horas, ou 120 créditos ECTS, e os cursos de licenciaturas com um mínimo de 4.860 horas, ou 180 créditos, ressaltando-se que a carga horária não representa “[...] as horas de contacto com os docentes e os créditos. Por exemplo uma aula teórica pode representar três horas de estudo por parte do estudante enquanto um seminário de duas horas pode necessitar uma semana completa de trabalho" (DGES, 2016). A continuidade acadêmica em nível de mestrado para os secretários egressos dos cursos de licenciaturas ocorre apenas em uma instituição pública, não sendo identificadas ofertas de cursos de mestrado integrado. $\mathrm{O}$ mestrado em Assessoria de Administração, oferecido ISCAP, visa formar profissionais para: “[...] Exercer atividades de assessoria ao mais alto nível da administração; Gestão de serviços administrativos; Secretariado de direção" (Iscap, 2016). Dada a exclusividade dessa oferta, expõem-se, a seguir, o quadro curricular do curso:

Quadro 3 - Quadro curricular do curso de Mestrado em Assessoria em Administração no ISCAP.

\begin{tabular}{ll}
\hline Unidades Curriculares & ECTS \\
\hline Assessoria e multimédia & 7 \\
\hline
\end{tabular}

Revista de Gestão e Secretariado - GeSec, São Paulo, v. 7, n. 1, p. 150-171,jan./abr. 2016. 


\begin{tabular}{ll}
\hline Gestão comercial & 7 \\
\hline $\begin{array}{l}\text { Sistemas de gestão da informação } \\
\text { Direito das obrigações e dos contratos ou cálculo financeiro } \\
\text { (optativa) }\end{array}$ & 7 \\
\hline $\begin{array}{l}\text { Psicossociologia das organizações } \\
\text { Relações económicas internacionais }\end{array}$ & 5 \\
\hline $\begin{array}{l}\text { Protocolo empresarial e institucional } \\
\text { Comércio electrónico ou inglês de Assessoria de administração } \\
\text { (optativa) }\end{array}$ & 5 \\
$\begin{array}{l}\text { Contabilidade de gestão } \\
\text { Direito da União Europeia ou análise financeira (optativa) }\end{array}$ \\
$\begin{array}{l}\text { Metodologias de investigação } \\
\text { Assessoria de empresas internacionais }\end{array}$ \\
$\begin{array}{l}\text { Dissertação/Trabalho de projecto/Estágio profissional (optativa) } \\
\text { Total }\end{array}$ \\
\hline daptado pelos autores de Instituto Superior de Contabilidade e Administração de Porto (2016). \\
\hline
\end{tabular}

Distinto da realidade portuguesa, o sistema de ensino brasileiro não só aloca os cursos de tecnologia no nível superior como, também, viabiliza a continuidade acadêmica a partir deles. Isso significa que os egressos dos e Cursos Superiores de Tecnologia (CST) podem ingressar em mestrados e doutorados, como permitido aos cursos de licenciaturas e bacharelados. A pósgraduação stricto sensu brasileira constitui-se em mestrados profissionais, mestrados acadêmicos e doutorados, sendo regulamentada no âmbito da Fundação de Coordenação de Aperfeiçoamento de Pessoal de Ensino Superior (Capes). Entre os critérios para a organização e o funcionamento desses cursos não consta a carga horária mínima. Já para os cursos lato sensu (especializações, incluindo os Master Business Administration) é definido o mínimo de 360 horas (Capes, 2016). Esses últimos não se tornam alvo desta investigação, pois embora estejam sob o acompanhamento da Capes, não atribuem título, apenas certificado de conclusão. Da mesma forma ocorre com o pós-doutoramento no Brasil. Ambos são considerados especializações de um título original de graduação ou de doutorado.

Os critérios para ingresso em cursos scricto sensu são definidos pelas instituições de ensino credenciadas para essa oferta, as quais gozam de autonomia para o estabelecimento dos requisitos de seleção dos futuros alunos. Cabe salientar que o ingresso prescinde de obrigatoriedade na sequência do mestrado para o doutorado, sendo possível, de acordo com as normas da instituição de ensino, ingressar-se no doutorado sem cursar o nível do mestrado. O órgão regulador desse nível de ensino mantém avaliações anuais e trianuais, bem como o controle sobre o número de vagas a serem ofertadas.

A formação superior para os secretários brasileiros podem ocorrer por meio dos CSTs, com o mínino de 1.600 horas, ou de bacharelados, com o mínimo de 2.400 horas. Ambas as formações 
recebem diretrizes do Ministério da Educação. No tocante aos cursos tecnológicos, a Resolução $\mathrm{CNE} / \mathrm{CP} \mathrm{n}^{\mathrm{o}} 3$, de 2002, em seu artigo $3^{\circ}$, estabelece:

São critérios para o planejamento e a organização dos cursos superiores de tecnologia: I - $o$ atendimento às demandas dos cidadãos, do mercado de trabalho e da sociedade; II a conciliação das demandas identificadas com a vocação da instituição de ensino e as suas reais condições de viabilização; III - a identificação de perfis profissionais próprios para cada curso, em função das demandas e em sintonia com as políticas de promoção do desenvolvimento sustentável do País. (Brasil, 2002, p.162). (grifo nosso).

A definição dos perfis mencionado naquela regulamentação consta no Catálogo Nacional de Cursos Superiores de Tecnologia, que "[...] apresenta denominações, sumário de perfil do egresso, carga horária mínima e infraestrutura recomendada de 112 graduações tecnológicas organizadas em 13 eixos tecnológicos". O curso de Tecnólogo em Secretariado está alocado no eixo Gestão e Negócios, tendo o seu perfil descrito como o profissional que:

[...] planeja e organiza os serviços de secretaria de centros decisórios de uma instituição. Aplicando conceitos e ferramentas tecnológicas específicas de assessoramento, de forma a otimizar os processos vinculados a suas atividades, este profissional assessora executivos, diretores e suas respectivas equipes, planeja, organiza, implanta e executa atividades e metas da área, eventos, serviços protocolares, viagens, relações com clientes e fornecedores, comunicação e redação de textos técnicos, além de gerenciar informações (Brasil, 2010, p. 40).

Os cursos de Bacharel em Secretariado são normatizados pela Resolução n ${ }^{0}$ 5, de 2005, a qual apresenta diretrizes para a sua organização curricular. Nessa regulamentação consta como perfil do egresso:

[...] capacitação e aptidão para compreender as questões que envolvam sólidos domínios científicos, acadêmicos, tecnológicos e estratégicos, específicos de seu campo de atuação, assegurando eficaz desempenho de múltiplas funções de acordo com as especificidades de cada organização, gerenciando com sensibilidade, competência e discrição o fluxo de informações e comunicações internas e externas. Parágrafo único. O bacharel em Secretariado Executivo deve apresentar sólida formação geral e humanística, com capacidade de análise, interpretação e articulação de conceitos e realidades inerentes à administração pública e privada, ser apto para o domínio em outros ramos do saber, desenvolvendo postura reflexiva e crítica que fomente a capacidade de gerir e administrar processos e pessoas, com observância dos níveis graduais de tomada de decisão, bem como capaz para atuar nos níveis de comportamento micro-organizacional, meso-organizacional e macro-organizacional. (Brasil, 2005, p. 79).

Os currículos desses cursos, conforme a mencionada resolução, devem conter conteúdos básicos, envolvendo as áreas de ciências sociais, jurídicas, econômicas e da comunicação e informação; conteúdos específicos, com técnicas e gestão secretarial, administração pública e privada, psicologia empresarial, ética e língua estrangeira; e conteúdos teóricos-práticos, com informática, estágio e atividades complementares. A monografia de final de curso não é obrigatória. 
Assim, as instituições de ensino podem decidir pela incorporação ou não desse componente ao currículo, desde que atribua a ele regulamentos específicos (Brasil, 2005).

A continuidade acadêmica para os secretários brasileiros formados nos CSTs ou nos Bacharelados podem ocorrer por meio de mestrados ou doutorados, porém, até o momento desta pesquisa, não se constatou cursos específicos para a profissão nesses níveis. Torna-se interessante observar que no período de 1999 a 2013, no Brasil, foram identificados 106 secretários executivos graduados com diploma de mestrado e dez com diploma de doutorado (Souza, Galindo, Martins, 2015). Em levantamentos complementares sobre tal contingente se constatou que, dos titulados em mestrado naquele período, apenas um é egresso do curso de Tecnólogo em Secretariado Executivo. Todos os titulados em doutorado são egressos dos cursos de Bacharel em Secretariado Executivo.

Os cursos superiores em Secretariado no Brasil iniciaram na região Nordeste, com o primeiro curso na Universidade Federal da Bahia (UFBA), por meio do ato de criação da Câmara de Ensino de Graduação e o Conselho de Coordenação daquela instituição, em 20 de janeiro de 1970 (Maurício, 2004), e o segundo na Universidade Federal de Pernambuco (UFPE), criado por seu Conselho Coordenador de Ensino e Pesquisa, em 3 de novembro de 1970 (Proacad/UFPE, 2016). No âmbito do ensino superior de tecnologia, a formação se inicia nas Faculdades Integradas Claretianas, instituição privada, que teve o curso reconhecido pela Portaria Ministerial $n^{\circ} 083$, de 27 de fevereiro de 1984 (como citado em MEC/Brasil, 2006). Em âmbito público estadual, o primeiro curso criado foi o de Automação de Escritórios e Secretariado em 1991, na Faculdade de Tecnologia de São Paulo (Motoyama, 1995), reconhecido pelo Parecer do Conselho Estadual de Educação n 274/96 e pela Portaria Ministerial n 853/96 (como citado em CEE, 2016). O cenário atual da oferta de formação superior para os secretários brasileiros é exposto no Quadro 4, a seguir:

Quadro 4 - Número de cursos superiores em Secretariado no Brasil autorizados, em fevereiro de 2016.

\begin{tabular}{|c|c|c|c|c|c|c|}
\hline \multirow[t]{2}{*}{ Nível de formação } & \multicolumn{6}{|c|}{ Modalidade } \\
\hline & \multicolumn{3}{|c|}{ Presencial } & \multicolumn{3}{|c|}{ A distância } \\
\hline Tecnólogo em & 71 & & & 17 & & \\
\hline \multirow{2}{*}{ Secretariado } & & Público & Privado & & Público & Privado \\
\hline & & 07 & 47 & & 0 & 17 \\
\hline Bacharel em & 97 & Público & Privado & Ac & & \\
\hline Secretariado Executivo & & 18 & 79 & 0 & 0 & 0 \\
\hline Total & 168 & 25 & 126 & 17 & 0 & 0 \\
\hline
\end{tabular}

Fonte: Elaborado pelos autores, com base em MEC/Brasil (2016).

Observa-se que, embora a formação tecnológica para os secretários brasileiros tenha se iniciado mais de uma década após a de bacharel, os CSTs já representam 42,26\% do contingente de 
ofertas em nível superior. Os cursos de bacharelados sofreram redução de 27,06\% em relação ao ano de 2012, quando totalizavam 133 cursos (Cielo, Schmidt \& Wenningkamp, 2014). Se em um primeiro momento esse quadro pode se mostrar mais promissor aos cursos CSTs, uma análise a partir da constatação de 82 cursos existentes em 2013 (Cielo, Schmidt \& Wenningkamp, 2014) indica uma retração de $13,41 \%$ também na formação superior tecnológica.

Talvez a análise sobre as razões para tal cenário encontre respaldo na constatação de que no Brasil, no período de 1972 a 2013, havia 40.014 secretários formados em nível superior (Sabino, 2006; MEC/Brasil, 2016), sendo que apenas 0,26\% desses egresos possuíam título de mestre e 0,01\% título de doutor. Isso implica quantidade de corpo docente oriundo do campo do Secretariado para a formação de secretários executivos, uma vez que a Lei n 9.394 de 1996, que estabele as Diretrizes e Bases da educação nacional, em seu artigo $6^{\circ}$ prevê que a "[...] preparação para o exercício do magistério superior far-se-á em nível de pós-graduação, prioritariamente em programas de mestrado e doutorado" (MEC/Brasil, 2015). A ausência de docentes diplomados em Secretariado nos cursos para a profissão pode promover um distanciamento nos discursos da prática pedagógica em relação às competências, habilidades e atitudes necessárias ao cotidiano secretarial, levando a um eventual esvaziamento nas matrículas e consequente fechamento dos cursos.

Embora a formação para o Secretariado no Brasil conste como requisito para a atuação no mercado de trabalho, distinguindo-se da realidade portuguesa, onde a profissão não é regulamentada, a análise comparativa sobre a formação nos países investigados indica a tendência de redução dos cursos superiores para os secretários, com a concentração futura na oferta de cursos tecnológicos, em detrimento aos cursos de maior duração. Identifica-se, também, que tanto os CTSPs como os curso de licenciaturas para o Secretariado em Portugal oferecem mais do que o dobro de carga horária dos CSTs e Bacharelados para a profissão no Brasil. Sobre esse aspecto, ressalta-se a distinção entre os sistemas educacionais daqueles países: no Brasil são contabilizadas horas em sala de aula e em Portugal, sob o sistema europeu, as horas são previstas como de estudo, não necessariamente em sala (DGES 2016).

Em relação às diretrizes para a formação tecnológica, considerando o Quadro Nacional de Qualificações português para os CTSPSs (ANQEP, 2015) e as orientações para os CSTs e bacharelados de Secretariado brasileiros (Brasil, 2002, 2005), observa-se uma maior aproximação entre os objetivos da formação em Portugal aos cursos de bacharelado no Brasil, indicando uma maior amplitude de conhecimentos e abstração para o desempenho profissional voltado a busca de soluções.

Revista de Gestão e Secretariado - GeSec, São Paulo, v. 7, n. 1, p. 150-171,jan./abr. 2016. 
A formação oportuniza o ingresso no mercado de trabalho de ambos os países, embora não na totalidade das vagas nas organizações portuguesas (Michael Page, 2016). No Brasil, a observação sobre as solicitações de estagiários de Secretariado indica a substituição da formação de bacharel pelo nível tecnológico. E mesmo esse nível já se apresenta em posição inferior no ranking dos estágios com maior bolsa-auxílio, o que pode suscitar certa desvalorização no mercado de trabalho. Embora não constando no escopo desta investigação, torna-se interessante considerar que a formação em Técnico em Secretariado (nível secundário no Brasil) que não constava no ranking dos dez estágios com maior remuneração no período no período de 2011 a 2013, passou a ocupar a décima posição no ano de 2014 (Nube, 2015).

Em uma análise global sobre o cenário brasileiro, pode-se inferir que além dos cursos de bacharelado para o Secretariado estarem sob redução na oferta, eles também se encontram em desvantagem sobre a empregabilidade em relação aos CSTs, os quais, por sua vez, podem vir a sofrer o mesmo declínio em relação aos cursos técnicos. Já em Portugal, a formação mostra-se mais promissora quanto à empregabilidade dos egressos, com tendência à incrementação no número de CTSPs. Dos dois países, a continuidade dos estudos em nível de pós-graduação stricto sensu é melhor oportunizada no Brasil, o qual não inviabiliza o ingresso nesses cursos a partir dos CSTs. No entanto, tal oportunidade não se demonstra explorada pelos egressos, podendo sugerir que há entre os estudantes o entendimento de uma profissão distanciada da necessidade de aprofundamento de estudos nesses níveis. Por fim, os resultados obtidos apontam que o quadro de formação tecnológica nos dois países carece de acompanhamento pelas instituições de ensino e pelos órgãos representantes da profissão, com vistas à avaliação sobre demandas e comportamento do mercado de trabalho, bem como expectativas dos estudantes e suas carreiras após egressos.

\section{Considerações Finais}

O histórico da formação superior em Secretariado no Brasil e Portugal, embora tenha poucos anos de diferença no início das ofertas, demonstra-se mais promissor em décadas passadas. Atualmente, a formação tecnológica vem ocupando maior espaço no universo de cursos, com progressão mais rápida em relação aos cursos de maior duração. Esse cenário recebeu incentivo das políticas para o ensino superior em ambos os países, que por sua vez se incluem em uma nova lógica do circuito universitário, provinda da diversificações de ocupações no mercado de trabalho. 
A relação educação-trabalho enfocada nos debates da Conferência Mundial sobre Educação Superior, em 1998, passou a constar nos sistemas de ensino como forma de garantir a competitividade das nações. No Brasil, a articulação das formações às demandas do mundo do trabalho já se anunciavam nas políticas de ensino superior desde a década de 1960, com o início de cursos tecnológicos. Essa modalidade brasileira recebeu reforço com as novas diretrizes do MEC de 2002, promovendo a expansão dos cursos. Tal evolução em Portugal se consolidou a partir de 2014, com a atribuição de nível superior aos cursos tecnológicos, os quais, embora não atribuindo grau acadêmico, passaram a integrar a estrutura formal da educação pós-secundária.

Não obstante a influência das políticas educacionais no ensino superior para a formação de secretários, o quadro que se apresenta no Brasil indica não apenas uma transformação no modelo de qualificação do Secretariado, mas, também, uma retração da formação por via dos estudos superiores. Como agravante tem-se, ainda, uma tendência na evolução da preferência para estágios pela formação em nível técnico sedundário. Em Portugal, embora os dados demonstrem uma expansão na empregabilidade dos secretários executivos, com considerável crescimento na oferta de vagas, ainda não se evidencia o interesse integral das organizações empregadoras por profissionais com a formação específica. Considerando que os cursos superiores naquele país iniciaram ainda na década de 1960, seria aguardada uma demanda já consolidada no mercado de trabalho.

Os desafios que emergem para o Secretariado sobre a sua formação em nível superior nos dois países se alocam nas políticas educacionais, no tocante ao acompanhamento dos debates e tendências para o ensino superior, no cenário para o emprego, referente à observação e articulação das demandas à preparação de novos profissionais, e no comportamento da população jovem, no tocante à identificação das influências nas expectativas e escolhas de carreira.

Dessa forma, entende-se que o presente estudo atingiu seus objetivos, podendo subsidiar investigações futuras com o aprofundamento em aspectos aqui identificados. Outras observações em níveis local, regional ou nacional poderão contribuir para a ampliação da compreensão dos caminhos que se esboçam para a formação de secretários nos países pesquisados.

\section{Referências}

ANQEP - Agência Nacional para a Qualificação e o Ensino Profissional. Quadro nacional de qualificações. Recuperado em 2 de dezembro, 2015, de http://manual.economatica.com.br.

Amaral, A. \& Teixeira, P. (2000). The rise and fall of the private sector in portuguese higher education. Higher Education Policy, 13(1), 245-266. 
Brasil. Lei $n^{0}$.6.556, de 5 de setembro de 1978. Dispõe sobre a atividade de Secretário e dá outras providências. Diário Oficial da República Federativa do Brasil. Poder Legislativo, Brasília, DF, 5 set. 1978, Seção 1, p. 14321.

Brasil. Lei $n^{\circ}$. 7.377, de 30 de setembro de 1985. Dispõe sobre o exercício da profissão de secretário e dá outras providências. Diário Oficial da República Federativa do Brasil. Poder Legislativo, Brasília, DF, 1 out. 1985, Seção 1, p. 14.314.

Brasil. Lei $n^{\circ}$. 9.261, de 10 de janeiro de 1996. Altera a redação dos incisos I e II do art. $2^{\circ}$, o caput do art. $3^{\circ}$, o inciso VI do art. $4^{\circ}$ e o parágrafo único do art. $6^{\circ}$ da Lei $\mathrm{n}^{\circ} 7.377$, de 30 de setembro de 1985. Diário Oficial da República Federativa do Brasil. Poder Legislativo, Brasília, DF, 11 jan. 1996, Seção 2, p. 393.

Brasil. MEC, CNE (2002). Resolução CNE/CP $n^{\circ}$ 3, de 18 de dezembro de 2002. Institui as Diretrizes curriculares nacionais gerais para a organização e o funcionamento dos cursos superiores de tecnologia. Diário Oficial da República Federativa do Brasil. Ministério da Educação, Brasília, DF, 23 de dez. 2002, Seção 1, p. 162.

Brasil. MEC, CNE (2005). Resolução CNE/CES n ${ }^{o} 3$, de 23 de junho de 2005. Diário Oficial da República Federativa do Brasil. Ministério da Educação, Brasília, DF, 27 de jun. 2005, Seção 1, p. 79

Castro, C. M. \& Levy, D. C. (2000). Myth, reality and reform in Latin American. Washington, D. C.: Johns Hopkins University Press.

Cielo, I.; Schmidt, C. M. \& Wenningkamp, K. R. (2014). Secretariado Executivo no Brasil: quo vadis? Gestão e Secretariado - GeSec, 5( 3), set./dez., pp. 49-70.

CBO - Classificação Brasileira de Ocupações. Códigos, títulos e descrições. Recuperado em 15 de março, 2012, de http://www.mtecbo.gov.br/cbosite/pages/pesquisas/BuscaPorTituloResultado.jsf.

CEE - Conselho Estadual de Educação/São Paulo. Renovação de reconhecimento do curso de Tecnologia em Automação de Escritórios e Secretariado. Recuperado em 26 fevereiro 2016, de iage.fclar.unesp.br/ceesp/textos/2001/772-2000.doc.

Coordenação de Aperfeiçoamento de Pessoal de Ensino Superior - Capes. Legislação específica. Recuperado em 27 de fevereiro, 2016, de http://www.capes.gov.br/avaliacao/sobre-aavaliacao/legislacao-especifica.

Curaj, A; Schott, P. Vlasceanu, L. \& Wilson, L. (Ed). (2012). European higher education at the crossroads: between the Bologna Process and National Reforms. New York/London: Springer.

DGES - Direcção Geral do Ensino Superior. Oferta formativa do ensino superior. Recuperado em 25 de julho, 2015, de http://www.dges.mctes.pt/DGES/pt/OfertaFormativa/.

$\begin{array}{ccc}\text {. Informações sobre o sistema de ensino superior português. Recuperado em } \\ \text { fevereiro, } & 28 \text { de } \\ \text { http:// }\end{array}$ 
http://www.dges.mctes.pt/DGES/pt/Reconhecimento/NARICENIC/Ensino\%20Superior/Sistema\%2 0de\%20Ensino\%20Superior\%20Portugu\%C3\%AAs.

- Declaração de Bolonha. Recuperado em 27 fevereiro 2016, de http://www.dges.mctes.pt/DGES/pt/Estudantes/Processo+de+Bolonha/Processo+de+Bolonha/

ECTS: European Credit Transfer System. Recuperado em 27 de fevereiro, 2016, de http://www.dges.mctes.pt/DGES/pt/Estudantes/Processo+de+Bolonha/Objectivos/ECTS/

Instituto Superior de Contabilidade e Administração de Porto (Iscap). Curso de Mestrado em Assessoria de Administração. Recuperado em 27 de fevereiro, 2016, de http://www.iscap.ipp.pt/site/php/mestrados.php?curs=18.

Gray, D. E. (2014). Doing research in the real world. London: Sage.

Majumdar, R. (2005). Marketing research: text, applications and case studies. New Delhi: New Age Internacional Limited.

Nascimento, O. O. (2007). Cem anos de ensino profissional no Brasil. Curitiba: IBPEX.

Maringe, F. (2006). University and course choice. International Journal of Educational Management, 20(6), pp. 466-479.

Maurício, B. M. D. P. (2004). Escola de Administração da UFBA: a trajetória de um centro de referência nacional. Dissertação de Mestrado, Administração, Universidade Federal da Bahia, Salvador, Brasil.

Michael Page. Balanço do recrutamento para área de Secretariado \& Administração. Recuperado em 28 de fevereiro, 2016, de http://www.aspsecretarias.pt/images/PR_Michael\%20Page_Dia\%20da\%20Secret\%C3\%A1ria.pdf.

MEC - Ministério da Educação/Brasil. Lei no 9.394 de 20 de dezembro de 1996. Recuperado em 23 de outubro, 2015, de http://www.planalto.gov.br/ccivil_03/Leis/L9394.htm.

MEC - Ministério da Educação/Brasil. Secretaria de Educação Profissional e Tecnológica. Portaria $\mathrm{n}^{\mathrm{o}} .119$, de 26 outubro de 2006. Aditamento de cursos superiores de tecnologia. Diário Oficial da República Federativa do Brasil. DF, 27 out. 2006, Seção 1, p. 31.

MEC - Ministério da Educação/Brasil. Sinopses estatísticas da educação superior. Recuperado em 25 de fevereiro, 2016, de http://portal.inep.gov.br/superior-censosuperior-sinopse. http://portal.inep.gov.br/superior-censosuperior-sinopse.

MEC - Ministério da Educação e Ciência/Portugal. Dados e estatísticos de cursos superiores. Recuperado em 27 de fevereiro, 2016, de http://infocursos.mec.pt/.

MEC - Ministério da Educação e Cultura/Brasil (2016). Instituições de educação superior e cursos cadastrados. Recuperado em 25 de fevereiro, 2016, de http://e-mec.mec.gov.br . 
Motoyama, Shozo. (Org). (1995). Educação técnica e tecnológica em questão: 25 anos do CEETEPS, história vivida. São Paulo: Universidade Estadual Paulista: Ceetep.

Nube - Núcleo Brasileiro de Estágios. Pesquisa nacional de bolsa-auxílio. Recuperado em 3 de agosto, 2015, de http://nube.com.br.

Portal Brasil. Saiba como é a divisão do sistema de educação brasileiro. Recuperado em 28 de fevereiro, 2016, de http://www.brasil.gov.br/educacao/2014/05/saiba-como-e-a-divisao-do-sistemade-educacao-brasileiro/view.

Portal Brasil. Matrículas em cursos tecnológicos aumentam 5,4\%. Recuperado em 28 de fevereiro, 2016, de http://www.brasil.gov.br/educacao/2014/09/matriculas-em-cursos-tecnologicosaumentam-5-4.

Porto, C. \& Régnier, K. (2003). O ensino superior no mundo e no Brasil - Condicionantes, tendências e cenários para o horizonte 2003-2025: uma abordagem exploratória. In: Seminário Internacional Universidade XXI: novos caminhos para a educação superior. Brasília: Ministério da Educação.

Portugal. Ministério da Educação e Ciência. (2006). Decreto-Lei no 74/ 2006. Diário da República, Lisboa, 24 de mar. 2006, nº 60, p. 2245.

Portugal. Ministério da Educação e Ciência. (2014). Decreto-Lei n ${ }^{o}$ 43/2014. Diário da República, Lisboa, 18 de mar. 2014, 1. ${ }^{\text {a }}$ série, n. ${ }^{\circ}$ 54, p. 2074.

Proacad/UFPE - Pró-Reitoria de Assuntos Acadêmicos da Universidade Federal de Pernambuco. Curso de Secretariado. Recuperado em 26 de fevereiro, 2016, de http://www.proacad.ufpe.br/index.php?option=com_content $\& v i e w=\operatorname{article} \& i d=168 \& I t e m i d=138$.

Ribeiro, I. (2008). Factores decisivos para a escolha do binómio curso/instituição: o caso do ensino superior agrário português. Revista Portuguesa de Educação, 21(2), pp. 69-89.

Sabino, R. F. (2006). A profissão de Secretário Executivo no Brasil: políticas para formação e emprego. Dissertação de Mestrado, Educação, Administração e Comunicação, Universidade São Marcos, São Paulo, Brasil.

Schwartzman, S. (2005). A expansão do ensino superior, a sociedade do conhecimento e a educação tecnológica. Rio de Janeiro: Instituto do Trabalho e Sociedade.

Souza, E. C. P.; Galindo, A. G. \& Martins, C. B. (2015). A produção acadêmico-científica no campo do Secretariado: mapeamento de dissertações e teses no período de 1999 a 2013. Revista de Administração Geral, 1(1), pp. 154-173.

Teddlie, C. \& Tashakkori, A. (2003). Major issues and controveries in the use of mixed methods in the social and behvioral sciences. In: Handbook of mixed methods in social \& behavioral research, pp. 3-50. 
Silva, S. Cursos técnicos de dois anos atraíram mais 2500 alunos para o ensino superior. Recuperado em 28 de fevereiro, 2016, de https://www.publico.pt/sociedade/noticia/cursos-tecnicosde-dois-anos-atrairam-mais-2500-alunos-para-o-ensino-superior-1711603.

Teicher, U. (1999). Responder às exigências do mundo do trabalho. In Conselho de Reitores das Universidades Brasileiras e Organização das Nações Unidas para a Educação, a Ciência e a Cultura. Tendências da Educação Superior para o Século XXI. Brasília: Unesco/CRUB.

Vieira, A. \& Sousa, S. O cenário do Secretariado em Portugal. Livro de Atas do Congresso Internacional de Secretariado e Assessoria 2015, pp. 9-20. Recuperado em 22 de abril, 2015, de http://loja.cpsecretariado.pt/WebRoot/ce_pt/Shops/291128/5537/7FDC/56CF/413B/4CD7/C0A8/80 0B/4272/Livro_de_atas_2015.pdf.

Wagner, A. (1998). From higher to tertiary education: evolving responses in OECD countries to large - Volume Participation. Washington, DC: The World Bank/Latin America and the Caribbean Regional Office.

Woodside, A. G. (2010). Case study research: theory, methods, practice. Boston: Emerald.

Yin, R. (2015). Estudo de caso: planejamento e métodos (5a ed.). Porto Alegre: Bookman. 